Devising the consumer of the competitive electricity market: the mundane meter, the unbundling doctrine and the re-bundling of choice.

Catherine Grandclément

https://orcid.org/0000-0003-0287-4425

catherine.grandclement@gmail.com

Alain Nadai ${ }^{1}$

CIRED, CNRS. France

https://orcid.org/0000-0003-0383-2729

nadai@centre-cired.fr

${ }^{1}$ Authors are listed alphabetically. They contributed equally to the work of collecting and analysing data and to the writing of the paper. 


\title{
Devising the consumer of the competitive electricity market: the mundane meter, the unbundling doctrine and the re-bundling of choice.
}

\begin{abstract}
This paper follows the sinuous trajectory of the joint design of an electricity meter and of the technical architecture of the smart home in France. The analysis points at the articulation between the mundane work of material and market design, and the profound, pervasive and political issue of agencing consumption. Three figures of the consumer appeared along with the evolving design of the smart home and meter: a behavioural energy saver; a market offer chooser and an attached consumer. The 'unbundling' doctrine which states that competition must be sorted out from monopoly in order for the electricity market to function was an often invoked argument to justify changes in the smart meter and smart home designs. The role of the doctrine was however ambiguous. As a rather abstract perspective on the working of markets, unbundling seems to be exceeded by concrete and mundane marketing attempts at re-bundling choice. And yet consumer figures doctrinally compatible with classical/neoliberal economics which consider the consumer as an autonomous self leave open the ground for an attached consumer to emerge, suggesting that the consumer is in fact always 'attached' rather than detached.
\end{abstract}

Word count: 10074 words 


\section{Introduction}

This paper follows a dispute between stakeholders about the design of a tiny portion of an electricity meter that is bound to equip every French household by 2021 . Along with the design choice of that tiny portion of the meter come choices about the general architecture of the smart home in France and the type of commercial interest and business models that may participate in the subsequently generated market. However this is not only a story of the structuring of the supply side of the meter but also of the demand side on which we will specifically focus. Indeed these design choices contribute to defining end-users as electricity consumers and to specify the agency they are endowed with. This is the topic on which this article concentrates.

In precisely describing the agency the consumer would be endowed with under different designs of the meter, we aim at engaging with a central tenet of liberal societies: the idea that the market is emancipatory because it allows individuals to autonomously enter into contact, exchange and leave, without one being under the control or influence of the other. In paying attention to the way the consumer is agenced through these designs, we will show that the consumer is in fact always 'attached' rather than detached.

This paper is divided in two sections. In the first section, we present the theoretical principles that guide our inquiry. They come from the extension of the "performativity programme' in economic sociology to the study of the consumer. In the second section, we review four possible technical configurations for the French smart meter that have been considered and debated in the course of the development of this meter. We also examine the figures of the consumer that accompany these technical designs. We pay special attention to the very material elements that are in this market to activate consumers and configure their choices. We conclude in showing that in the name of the market and to the supposed social progress it brings, a great deal of demarcation work between the 
market and the political is enforced while in fact a lot of political work passes unnoticed in the mundane meter.

\section{Devising the consumer of the competitive electricity market - some preliminary conceptual points}

\subsection{A device-oriented inquiry into consumer agency}

That human beings have become consumers is a reality which a variety of approaches in the social sciences have set out for many decades to describe and critically analyse. The approach of this phenomenon however evolved markedly after the cultural turn of the 1970s. Social sciences studies traditionally privileging the production side of industrial societies started to reconsider the demand side not as a passive or even manipulated receptacle but as a space of autonomy and a source of creativity and agency (du Gay, 1996; Lury, 1996). New subfields of research in anthropology, sociology, business science and other disciplines emerged and now devote themselves to the study of consumption and the consumer (see for instance the works of Daniel Miller [1997], Elizabeth Shove [2003] and the Consumer Culture Theory field [Arnould and Thompson, 2005]). Along with the re-evaluation of consumption practices in the social sciences came an extension of consumer identity to encompass nearly the whole life of individuals, sometimes interwoven with other, non-market areas of life from education to culture and from migration to family making (Storper, 2000; Trentmann, 2006, see also Schwarzkopf, 2011), including, recently, work and the production side (Dujarier, 2011). Consumption was then also reconsidered as a site of collective organization, resistance and political mobilization (Dubuisson-Quellier, 2009; Chessel, 2012).

While the expansion of the language of consumption beyond the market is notable, there is still a lot to be said about the consumer in the market and specifically about the consumer as a subject to be governed through the market. Michel Foucault is famous for, 
among other things, having explicated how the claim to individuals' autonomy in liberal societies is answered through the market while the market is also a device through which individuals are governed - in a deflective way since individuals are not directly controlled by an external identity but shape their conduct according to the norms carried through the device (Foucault, 2004). The notion of a device, familiar to the work of Michel Foucault, is also crucial to the strand of research known as the 'performativity programme' and in which we find operative resources for our inquiry into the structuration of the consumer's capacity to act by the electricity meter. The performativity programme is a radically constructivist approach to economic action put forward by Michel Callon whose core insight is that the economy doesn't lie out there waiting to be 'discovered' or described by economics (Callon, 1998; Callon, 2007; Callon and Muniesa, 2005 ; MacKenzie et al, 2007). Rather economics invents the economy (Breslau, 2003; Mitchell, 1998, 2008). The knowledge of economists isn't just descriptive, it is performative in the sense that it participates to put in place, realize and hold the economy (Callon, 2007). The performativity programme follows suit with the essential Actor-Network-Theory contention that agency is distributed in networks or devices composed of various types of tools and texts and which can be called 'assemblages' or 'agencements' (Callon, 2007, 2016; Muniesa, 2014). This line of research has been prolific in producing several works dedicated to bringing to light the complexity and fullness of actual market devices (Callon et al., 2002; Callon and Muniesa, 2005; Callon et al. 2007; Araujo et al., 2010; Callon et al., 2013 ; Geiger et al., 2015 ; Cochoy et al., 2017). According to this view, the consumer can be understood as an actantial position materially supported or enabled by agencements (Muniesa et al., 2007; Muniesa, forthcoming). What is going to be sorted out as political, moral, technical, economic, and as consumer or consumed is an aftereffect of the agencement, not its ex-ante components. 
Building upon Foucault's insight, on the one hand, and on the performativity programme in economic sociology on the other hand, a series of recent works have brought the study of the consumer to new edges (Fridman, 2010; McFall, 2014; Ariztia, 2015; DubuissonQuellier, 2016; Cochoy et al., 2017; Breslau, 2018). These works show how consumers are assembled, performed and, depending on the case studies, mobilised or governed through market devices. As Daniel Breslau (2018) puts it, the performativity approach replaces the subjectivist definition of economic actors by one in which the actor is an emergent effect of an assemblage of devices. This opens up the possibility for an inquiry of consumer agency through a close-by reading of the devices that configure this agency. Breslau examines the construction of the consumer in a very similar context to the one we study in this paper, that is, the effort made in the electricity sector to implement a consumer that would react to a variety of signals - actually, price signals in Breslau's work. That reactive capacity is often associated with 'smart' projects in the electricity sector and it is worth noting here that the birth of a smart consumer is a founding aim of those projects across the world, as is amply studied in a recognizable part of the burgeoning literature on smart grids in social sciences (Skjølsvold et al., 2015). Few works, however go further than the analysis of the imaginative and putative part of the consumer side of the smarting of electricity. Breslau's work is a notable exception in its decryption of how specific devices placed inside homes contribute to the 'assembling' of the smart consumer. But while Breslau is interested in linking the genesis of the devices that configure the electricity consumer to political struggles for the definition of the market, we propose to enter even further in the scrutiny of the political implications of the technical details of devices intended to structure the consumer. We do so by taking stock of the notion of 'script' as put forward by Madeleine Akrich (Akrich, 1992) to analyse the working of technical objects. The notion of script stems from a material- 
semiotic approach to techniques that points to the fact that users are always already contained, even in a weak or excluding way, in technical objects under the guise of 'scripts' which are ideal scenarios of use written in the technical design of the object. Users however retain an agency in the use of objects and devices as scripts are almost never executed as intended (Akrich, op. cit.; Wyatt, 2003). In particular, 'scripts' that form part of programmes of action are regularly countered by 'anti-programmes' that leads the initial programme to adapt and in turn, the anti-programme to adapt further, leading to a dynamic of innovation that stabilizes when enough of the anti-programme have been incorporated into the programme (Akrich and Latour, 1992).

\subsection{Market unbundling and market devices}

In what follows, we study the evolving story of the design of a new electricity meter in France around the year 2013 in connection with the (also evolving) discourse on the consumer that justifies such design. But we do not just describe the design and the rhetoric, we also pay close attention to the technical design of the meter and how, if realized, it would 'script' a certain version of the electricity consumer. To use another term from the performativity programme for the study of markets, we study how the consumer is devised, that is inscribed into devices, namely, here, the electricity meter. We emphasize the material dimension, the tools and engineering efforts needed for so devising the consumer. In precisely describing the agency the consumer would be endowed with under different designs of the meter, we aim at engaging with a central tenet of liberal societies: the idea that the market is emancipatory because it allows individuals to autonomously enter into contact, exchange and leave, without one being under the control or influence of the other (Rosanvallon, 1999). In other words, in a market, the relationship between producers and consumers is supposedly not one of power of one upon the other. The sides taking part in the exchange do so autonomously. 
This feature of markets translates in the notion of choice and then in that of freedom of choice as the most fundamental freedom of contemporary societies.

As a consequence, economists devote a lot of their work to ensure that the conditions of choice are fulfilled, which means having competition and no domination even if there are dominant actors -- that things happen "as if" the formalist conditions of competition were fulfilled and not because of the effective composition of the market is the tremendous change brought to anti-trust rules in the US by the "Law and Economic" School at the University of Chicago (Davies, 2014). In Europe, the liberalization of the electricity sector instituted competitive markets down to the residential sector (Jabko, 2006). This was carried on through a distinction between, on the one hand, the network part of the electricity system that is considered a "natural monopoly" and remains regulated and, on the other hand, the production part upstream and the retail part downstream which are both organized as competitive markets. This distinction is called 'unbundling', meaning that the formerly tight integration of the electricity system has to be decomposed, 'unbundled'give way to two separate parts: one in competition and the other one under regulation. Unbundling means marking a strong distinction between the grid described as a neutral public service infrastructure and upstream and downstream activities open to free market competition amongst multiple energy producers and providers. 'Unbundling' is at the core of the Third Energy Package of the European Union, a legislative package adopted in 2009 and aimed at establishing a unified electricity market. National regulatory authorities, such as the French 'Commission de Régulation de l'Énergie' (CRE), have been established by this package, so as to ensure the implementation of the doctrine of unbundling in Member States and the good functioning of the electricity 
market ${ }^{2}$. In France at least, 'unbundling' has become a crucial keyword of any reflection about the future of the electricity system. The dominant actor of the system, EDF (Électricité de France), with its regulated subsidiary and its competitive subsidiaries pays a lot of attention to the frontier between the regulated and the competitive parts of the electricity system. In order to respect the unbundling doctrine, it is crucial that the regulated part be neutral toward the competitive parts and that the competitive parts do not enter in regulated territories where it could benefit from unfair market advantages or even a monopoly situation. In contrast with the notion of "natural monopoly" (Mosca, 2008), "unbundling" might not be a canonical term of economics. It is nevertheless constantly used by the actors of the French electricity system, including its regulator, in reference to the proper economic organisation of the sector. Unbundling must be respected! While the founding claim of the performativity programme was that economics was not merely describing the economy but actually participating in its constitution, performing it, economics is not alone in that performation. There is a variety of knowledge and professionals which take part in the constitution of market devices (Callon, 2007). The unbundling case is then very similar to that studied by Daniel Breslau (2013) in the US where lay economic concepts are mobilized in the construction of a

${ }^{2}$ The national regulatory authorities coordinate at the EU level through the Agency for the Cooperation of Energy Regulators (ACER). The Third Package actually advocates 'ownership unbundling', the fact of splitting the ownership of production and retail of electricity from that of its transmission infrastructure. Ownership unbundling is supposed to grant free competition in an open marketplace by avoiding vertical integration, a situation in which the supply chain of a company is owned by that company. German and French Member States however have exhibited a strong reluctance toward ownership unbundling (Jabko, 2006). In France, EDF, the state company that previous to 1996 was in a monopoly position, went through an "accounting unbundling" of its different parts (production, grid, provision) but remains integrated as to its ownership (about $80 \%$ by the French state). 
specific type of electricity market (a capacity market). Breslau recognises it as an instance of 'performation' of the economy by economics even though the economics in question are not carried on by "validated" economists.

Unbundling, as a notion aimed at performing a neat separation between market and nonmarket domains, can be regarded as a declination of the contemporary belief in the progressive force of the market. In markets where competition is pure and perfect, individual consumers equipped with a set of subjective preferences, faced with multiple market offers and complete information can at the same time express their freedom of choice and drive market configuration toward a collective (social) optimum. So goes the ideal economic rhetoric articulated around a version of the consumer as a chooser. The individual is a self-contained totality that holds within him or her their (stable) preferences. The final choice comes from the confrontation between these preferences and the alternatives available out there. It is this version of the consumer that the unbundling doctrine seeks to perform. Unbundling means keeping the non-market separated from the market, or rather keeping the monopoly separated from the competitive area so that one is not contaminated by the other and atomized individuals can be put in front of free choices.

The current literature in market studies which we briefly surveyed above and which put agencements and devices at its core constitutes a radical departure from this kind of vision. According to the market agencement literature, action is always collective and distributed. Not only is the consumer never "naked", stripped of affects and social ties as economics would have it and as the classical economic sociology critique would put it, but above all, the consumer can never be separated from the agencement that brings it into existence. One important consequence is that in any market agencement, there is a multiplicity of intermediaries that coproduce the choice with the consumer as clearly 
demonstrated by Franck Cochoy, using the case of shopping at the supermarket (Cochoy, 2002; Cochoy and Grandclément, 2005). More recently, a specific conceptual effort has been put toward analytically grasping the agencement of consumers, the production of attachments between consumers and goods and the exploration not only of devices but also of dispositions which was until then notably under-studied (McFall, 2014a and b ; McFall et al., 2017). In this line of work, contrary to the view of consumer action put forward by economics, the action of the consumer does not depend on the enforcement of norms (of competition, of information, and so on) but on the configuration of the assemblage that will enact consumer action. According to this vision, the consumer is never the self-contained heroic individual of economics but always the momentary effect of a heteroclite compound. The consumer is always already attached in multiple ways to devices.

\subsection{Mundane market devices and the unnoticed political work of the market}

The case study presented in this paper aims at pointing out three successive versions of the consumer as they were invoked in the dispute that went on around the year 2013 among various stakeholders about the material design of the French smart meter. The first is the 'market offer chooser' of classical economics, the second is the 'behavioural energy saver' that is a mix of behavioural economics and environmentalists' attempt at rearticulating practices and the third is the 'captive' consumer of marketing practices. Our aim is to explore how consumer agency is devised through the tiny details of the material design of the meter and how this gets articulated with the big issue of what is a choice and an act of consumption. In doing so, the analysis points at an articulation between the mundane work of material and market design, and the profound, pervasive and political issue of agencing choice (Neyland et al., this issue). In several regards, the case points at an ambiguous role of unbundling. As a rather abstract perspective on the working of 
markets, unbundling seems to be exceeded by concrete and mundane marketing attempts at re-bundling choice. The profound lies in the mundane that is the tiny details of these practices. Yet, in overlooking these mundane practices of market making, the 'unbundling' doctrine also sets an order which qualifies market as the unregulated (apolitical) territory and allows these practices to proceed unnoticed to their (political) work of agencing choice. Unbundling is thus also pervasive and profound in that it sets the conditions for that political work to happen unnoticed through the market. We thus join with recent works on the political work of markets that emphasize that politics is in the inside of markets not on the outside (Kjellberg and Helgesson, 2010; Geiger et al., 2015; Callon, 2016; Ansaloni et al., 2017). The notion of the mundane offered by Neyland et al. (this issue) however draws attention toward the demarcation work between the unnoticed - or unnoticeable -- (the mundane, the ordinary, the market) and the officially noticed - or noticeable (the political) while both - the market and the political - hybridize, which the vocabulary of the mundane aptly puts in tension in pairing the ordinary and the profound.

\section{The successive configurations of meter design and of consumer agency}

\subsection{Presentation of the case study}

Our analysis is based on a seemingly minor episode of the large, public and still on-going protest against the deployment of a smart metering infrastructure in France. That minor episode which concerns a small technical component of the French smart meter has however large-scale consequences for consumers and businesses. What is at stake in this dispute is how end-users are defined as electricity consumers and with what type of agency. This story is reconstructed from a small set of interviews at key institutions of 
the smart meter programme ${ }^{3}$. While our interviews were intended to be exploratory and took place with high-profile managers that would supposedly have a broad overview of the issue at stake, in the course of the interviews, we found ourselves propelled into a minutiae of technical details about the smart meter design. Each of these technical details was in fact a move in a political and economic battle (Latour, 1996; MacKenzie, 1990).. What was at stake was the role of the consumer and its capacities to act in the renewed electrical world of the smart grid. The story we recount however is only one moment in a long and largely subterranean dispute over the smart meter design, which is still progressing up to this day. The end point of our case study is not the final stage of a story which has since evolved again and has yet to be reached. What matters to us is less the end point of the story than the more conceptual point about the ambiguous relation between a rather abstract economic doctrine instantiating a societal belief in the emancipatory capacity of market and the mundane activity of market making through tiny practices of technical design.

\subsection{The role of the meter in the smart home in France}

\subsubsection{The smart home as a land of opportunity}

The smart electricity grid is a technological project that aims at fully doubling the electrical network with a telecommunication network which means that the grid would be "bi-directional", allowing technical benefits for the grid and a much better integration of demand in the management of the electrical system. The smart grid project comes accompanied with many projects for 'modernizing' electricity consumption and the

\footnotetext{
${ }^{3}$ We conducted a total of 8 interviews in May 2014 and March 2016 at the following institutions: the grid operator, the Energy Regulator, the Ministry of Energy, the Energy and Environment Agency, the $R \& D$ of the national electricity company, the Energy Ombudsman.
} 
home, which would now be called the 'smart home'. From the point of view of the grid operator, the home would then become a resource for grid management. For instance, when demand is high or supply is low, technical devices could automatically interrupt the washing machine or the fridge in a way that engineers consider as non-detrimental to the washing process or to food conservation. From the point of view of a series of businesses such as telecom operators, internet companies, energy providers, home appliance manufacturers, start-ups of all kinds, and so on, the electric smart home is a field of market development, a land of opportunity perhaps, where business models are speculatively imagined. The sketch below is a technical diagram of how a "smart home" could work. A box receives direct load-control orders or price signals and communicates through waves or wires with the electrical appliances of the home. This smart home does not need a smart meter to work.

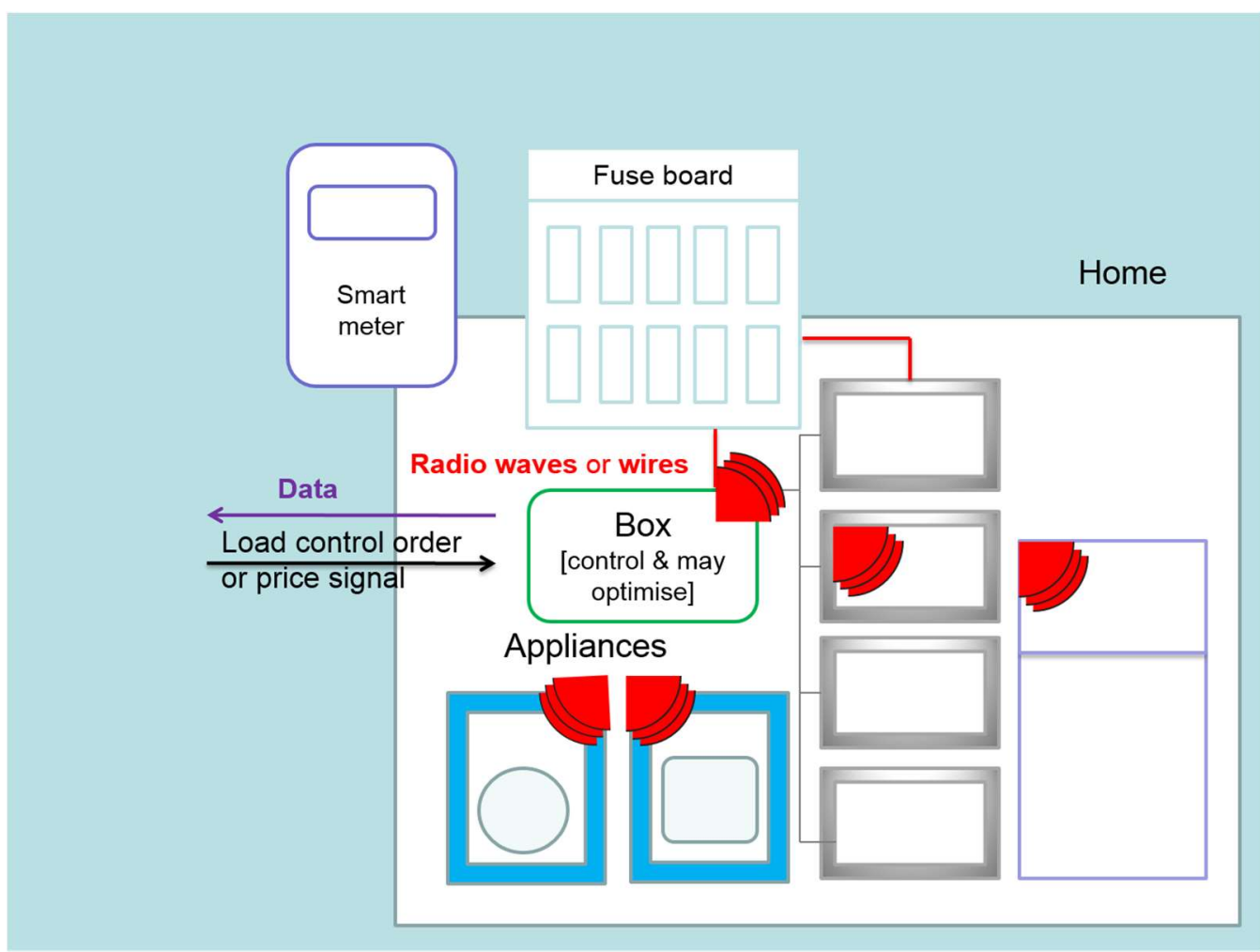




\subsubsection{The merging of the smart meter and the smart home in France}

In France, a large-scale smart meter roll-out started in 2010 with a 6-month pilot phase during which around 300,000 meters were installed. The pilot phase generated a heated debate and lots of criticisms of the (single type of) French smart meter. In parallel, an important smart grid programme endowed with hundreds millions of euros started in 2008. This programme funded "demonstration projects" that gather industrialists around "real-size" projects of technical innovation. In June 2011, at a moment of heightened criticism of the meter and while promoters of the project raced to speed up decisions on the smart meter deployment, a new call for tender for smart grid demonstration projects was issued. This call imposed the French smart meter as an obligatory passage point for such projects.

The initial smart meter project in France was however not specifically designed to support demand-side management functions. Its aims were rather to automate meter readings in order to save on reading costs and improve bills accuracy, to prevent electricity stealing, and to monitor consumption at the level of a neighbourhood. Thus, the June 2011 funding scheme for smart home projects made two independent projects (smart meter and smart home) intersect. It led to embedding smart home functions inside the smart meter.

Within this context, an empty slot, already present inside the meter, became the centre of attention as it could effectively accommodate a "radio module" which would transmit waves to home appliances and endorse smart home functions (see figure 2). 


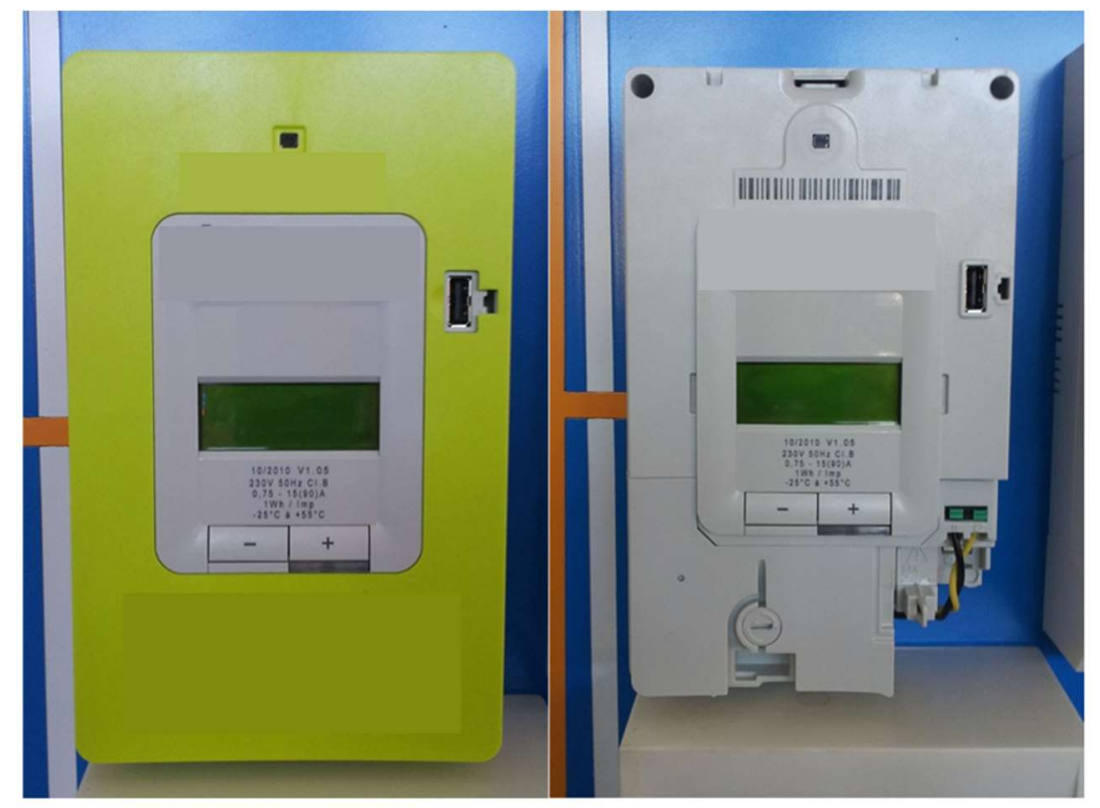

\subsection{The evolving design of the smart meter and of the smart home}

Since smart home projects now had to pass through the meter, the design of both the meter and the smart home had to be reconsidered. As can be seen in figure 3 , the box that served to control appliances in figure 1 has disappeared and its functions go through the meter.

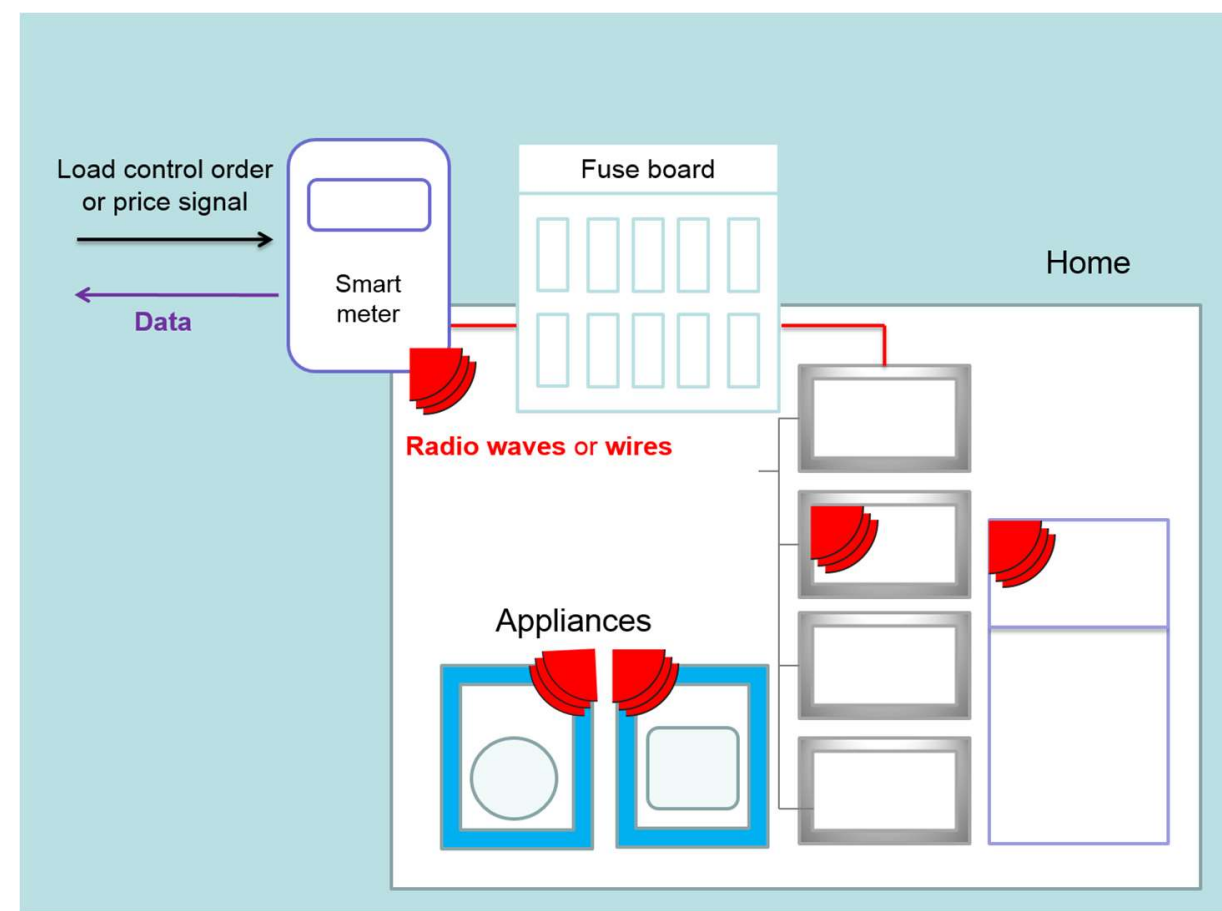




\subsubsection{Enabling the 'behavorial energy saver' consumer}

In order to be fully deployed, the smart meter programme had to prove that it was beneficial (the cost-benefit analysis should be positive ${ }^{4}$ ). Energy savings for the endconsumers were key to the expected benefits of the smart meter deployment. Around the year 2010 a series of studies circulated in the electricity sector which tended to show that real-time and easily available information - called 'feedbacks' in the jargon -- about one's energy usage inside the home would induce energy savings on the part of householders (Darby, 2006; EPRI, 2009; Ehrhardt-Martinez, 2010). The European Smart Metering Industry Group - an interest group - commissioned a meta-study in 2011 and another in 2012 in order to arbitrate the on-going dispute about the level of energy savings possibly attainable through the provision of feedbacks (Stromback et al., 2011; Lewis et al., 2012). In spite of blatant methodological flaws (for instance, an energy saving mean value calculated on gross results of different experiments conducted in countries with different average electricity usage and level of equipment), these studies quantify the often positive effect that the provision of 'energy feedbacks' has on energy consumption. In France, energy savings from smart meter feedback was the adjustment variable that made positive the cost-benefit analysis of the smart meter programme. In effect, quantification of energy savings due to information provision depends on hypothesis that can tremendously alter results (Cour des Comptes, 2018). Behind the dispute on the quantification of expected energy savings lies a vision of the consumer endowed with behaviours that change

\footnotetext{
${ }^{4}$ This is a requirement of the European directive which gives an objective of equipping with smart meters a minimum of $80 \%$ of consumers across all member states by 2020 , provided that the cost-benefit analysis is positive. Directive 2009/72/EC of the European Parliament and of the Council of 13 July 2009 concerning common rules for the internal market in electricity.
} 
according to information. Such a behaviourist version of the consumer is typical of the Attitude, Behaviour, Change or ABC model of society that is common in energy policy circles (Shove, 2010).

In our case study, however, this behavioural figure is invoked in two ways and by different actors. It is first part of EU's and the French energy agency's generic rhetoric for making up an 'active' consumer, who, once embedded in an appropriate informational environment, may save energy and contribute to peak load shedding in the electrical grid (Abi Ghanem and Mander, 2014). Part of this rhetoric comes from the 'fixing' of the obvious limitations of microeconomics vision of consumer ratonality by works of experimental psychology which offer a means to repatriate individuals' cognitive biases inside micro-economics - and to correct those biases, most notably under the guise of 'nudges' (Thaler and Sunstein, 2008), all other things remaining the same in the discipline (Davies, 2014). In contrast, consumer associations invoke the provision of real time price and quantity information about energy consumption as a way to make energy consumers more aware of their energy use and perhaps rearticulate their practices in a more collective way (Marres, 2009; Bulkeley et al., 2014 ; Throndsen and Ryghaug, 2015; Naus and van den Horst, 2016; Skjolsvod et al., 2017).

The smart meter, however, only had a small and not easy to read screen. In addition, meters are often located outside the home or deliberately hidden from sight (concealed in a cabinet with the fuse box, for instance). It thus seemed unlikely that consumers would regularly check their meter, collect information and modify their electricity usage accordingly. Criticisms arose. The energy and environment agency issued a negative rating for the meter. A consumer organization noticed that consumers would not only have to bear the cost of the meter but also to pay for an additional display device in order to actually make the informational promise of the meter come true. As a response to these 
criticisms, in January 2012, a ministerial order required that smart meters have : i) an interface accessible to the consumer for information display; and ii) the potential to transmit data so as to enable the remote control of appliances ${ }^{5}$. Clearly, the French smart meter alone was not fulfilling these requirements.

Due to the presidential and general elections in 2012, the smart meter project was halted for several months. In November 2012, a working group on the meter was set up by the newly elected Environment Minister. The working group comprised industry stakeholders, administrative bodies and consumer organisations. It was supposed to address financing aspects, functionalities, schedule, health issues, technical standards, etc. A subset of this working group was devoted to the 'radio module' of the meter. The technical design of the radio module, as well as the types of market design and the associated positions of the consumer that came with it, became the topic of a struggle. Consumer associations, the energy and environment agency and the energy ombudsman seized the working group as an opportunity to defend consumers' benefits and demand that the smart meter provide information in a way that would promote energy saving behaviours. More precisely, they asked for the radio module to serve this purpose and that 30 million meters be equipped with an in-home display. The module could then radiotransmit information about one's electricity usage to a screen (the in-home display) that would be provided to everyone along with the meter (see figure 4).

It was thus proposed that a communicating radio module and an "in-home display" be installed with each smart meter as part of the public service of electricity. After all, the meter itself had been introduced with an argument of public service and equality of access

\footnotetext{
${ }^{5}$ Order of 4 January 2012 pursuant to Article 4 of Decree No. 2010-1022 of 31 August 2010 on metering devices on public electricity networks.
} 
in a typical manifestation of the 'infrastructural ideal' (Graham and Marvin, 2001) that is markedly strong in France. A single type of smart meter was to be installed in all 30 million homes of metropolitan France. Information provision could as well be considered a public good and not something to be subjected to market dynamics.

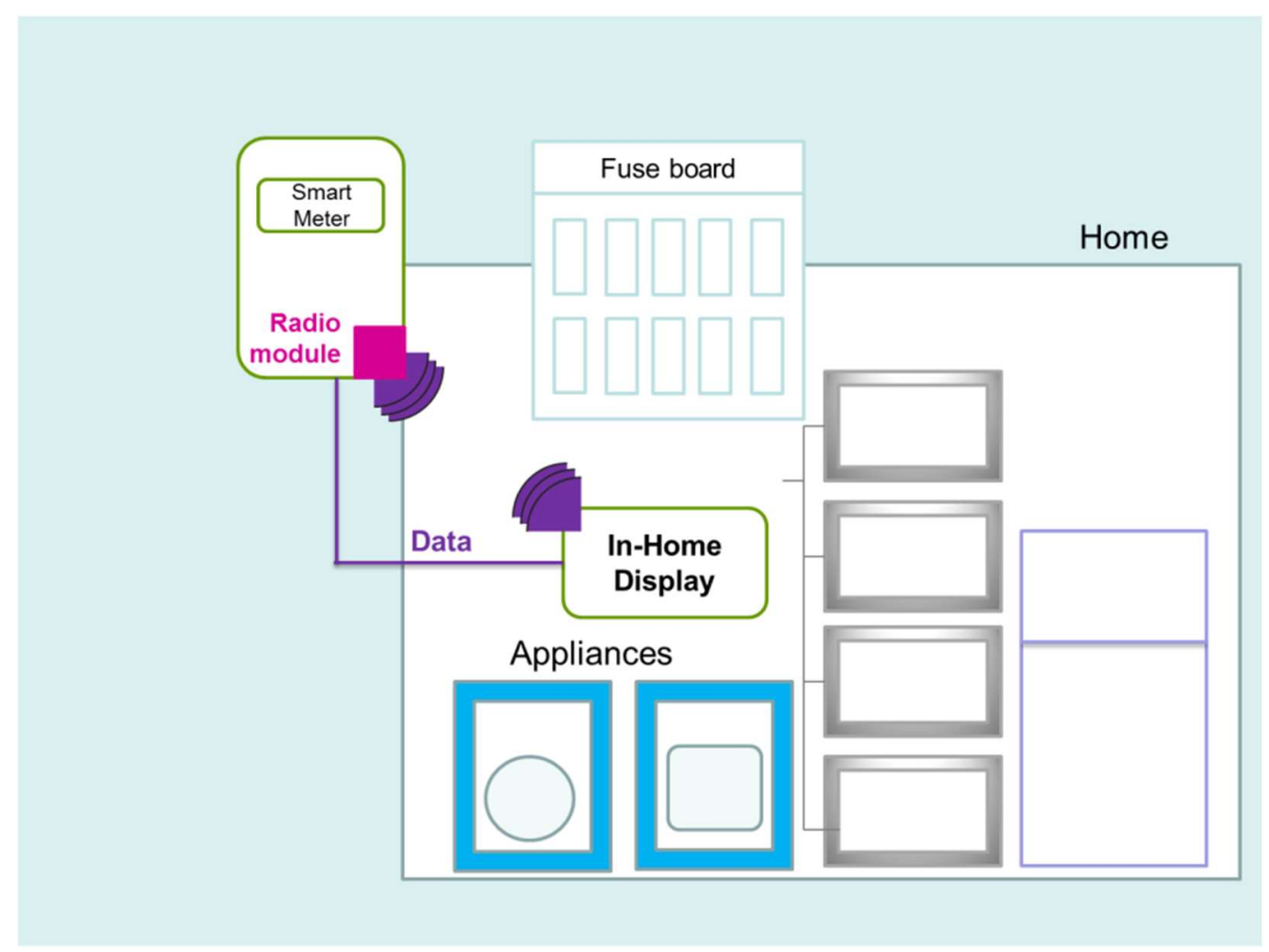

The regulator however ruled against the universal provision of radio modules and inhome displays. It justified its position with reference to the unbundling doctrine, mobilized in a spatialized mode that distinguishes where public service ends and where market begins. Upstream from the meter is the natural monopoly of the grid operated by a regulated public company (grid operator). Downstream from it is the realm of the market with several companies competing for energy provision (energy providers). The meter itself is situated in the domain of the public good. It is understood as a flat interface between the two domains, and anything which is plugged in 'after' (or downstream from) the meter is part of the domain of market competition. 
This spatial-political order would be disturbed if the grid operator or indeed any public service operator was to provide a data display 'beyond the meter' and if it was to do so as a universal or basic service to all homes. Should this happen, the spatial boundary between the market and the regulated infrastructure would be fractured. A public good would enter the downstream domain, it would enter peoples' homes - posited as the realm of the market - and in so doing it may distort competition. So for the in-home display: a publicly provided in-home display would intrude, even protrude in the neat division between infrastructure and market that is a founding tenet of market liberalisation in the electricity sector in Europe.

In addition, the energy regulator and energy providers saw the provision of data about energy usage as a service that could be commodified and thus as something that should be delivered through the market rather than as a public good. Providers had already formulated business models based on the telco industry: they expected to offer consumers energy and energy services in new, commercially viable bundles, for example by offering specific tariffs and energy displays. The idea that in-home displays would be provided to everyone as part of the basic public service would instantly invalidate these business models. If providers were no longer able to compete on elaborate bundled offers (including rates and smart displays) but only on bare prices, they would soon enter a ratrace competition to the bottom. From their point of view future benefits were fast evaporating.

The energy regulator insisted on drawing a clear line between the meter and the home because the meter is part of the natural monopoly of the electricity network which is regulated. The interface (apps, website, displays....) was to be supplied by the market and fully positioned on the consumer side. However, in order to satisfy the January 2012 ministerial order, it was decided that a simply-designed public service website would be 
set up, where the customer could log in and retrieve some information about his/her electricity usage (figure 5).

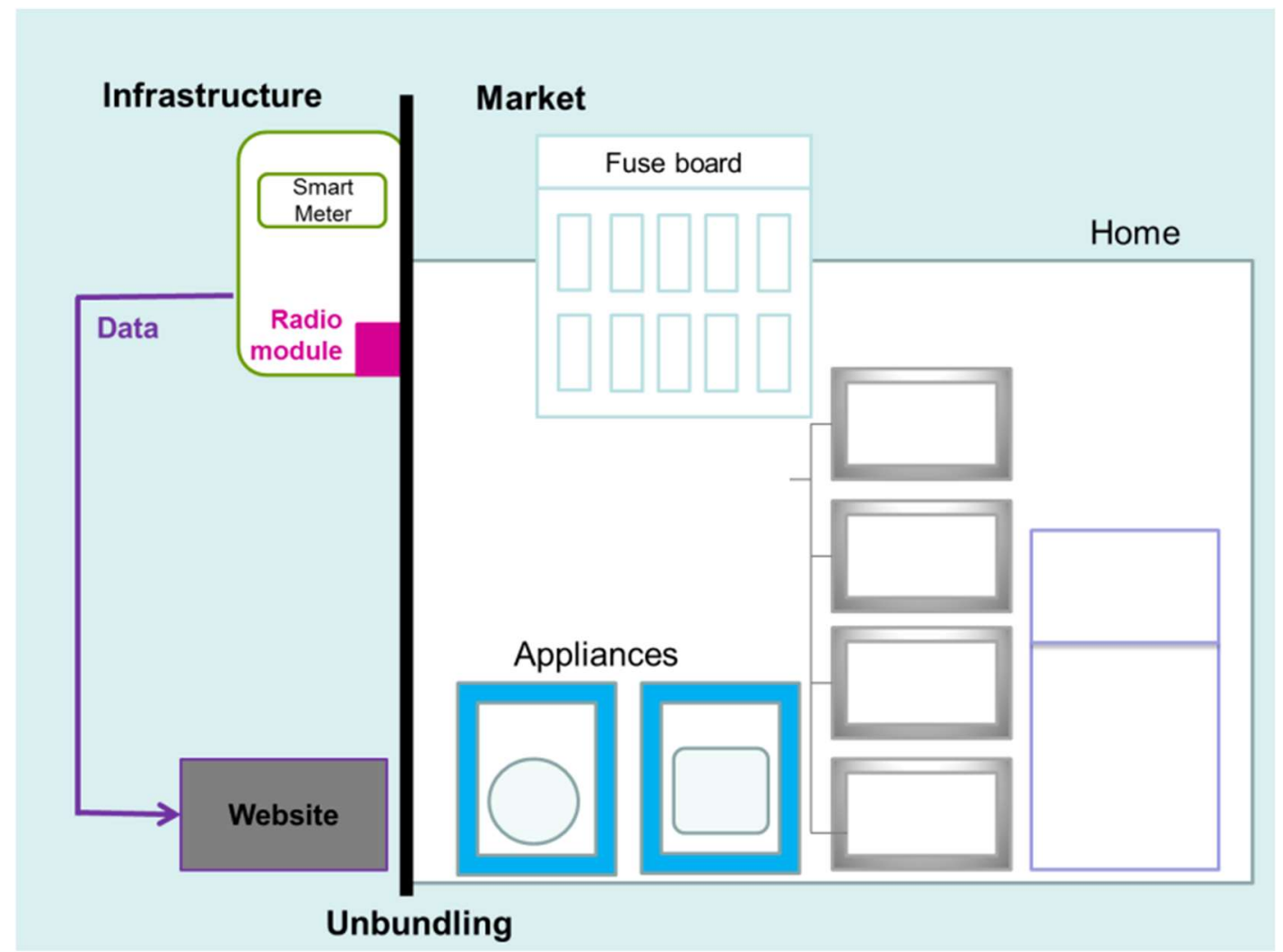

\subsubsection{Keeping the meter neutral and activating the market offer chooser}

The discussions about using the radio module as a gateway for the in-home display opened up exchanges about which data would be made available to the consumer. The ombudsman and consumer organizations took for granted that price data would be available in and through the meter. It was expected that the consumer could go and buy a display device and plug it into the meter in order to display energy prices and consumption at home. Price information was anyway needed in order to manage appliances which is an assumed objective of the smart home programme.

The surprise was thus great for some in the working group when this assumption was not backed up by the discussions. Not only would technicalities limit the meter in managing multiple and dynamic price fields but the energy regulator again opposed this eventuality. 
According to the regulator, unbundling required the regulated grid operator not to interfere with market coordination. This meant that the grid operator should not access market data such as electricity retail prices. Even though the consumer needs electricity rates to manage its appliances, those rates shall not pass through the meter. Again, this was justified by the unbundling doctrine, the need to demarcate the market from the nonmarket and to prevent these interests from mixing.

Eventually, a compromise was found: price-menus could be inscribed as hierarchical indexes in the meter. As proxies for prices, indexes could inform the consumer about the hierarchy of pricing while not revealing the exact real prices to the grid manager. Yet, as emphasised by the ombudsman, they would not allow genuine optimisation. Yes, index 2 is more expensive than index 1 but by how much? Is it worth the effort to defer consumption when index 2 is active? Consumer-led demand-response outside the prepackaged offers of energy suppliers (who know their prices) could then only remain limited. The decision was thus again justified by a boundary argument: the market as a space of private interests had to be clearly separated from the space of collective infrastructure and public interest.

In the working group, discussions about the radio module also progressively rendered explicit another project involving this module. Some actors intended to use the radio module to carry on the usual functions of energy management boxes that is to control appliances. One advantage of using the radio module for demand response functionalities (instead of using it for the systematic plugging of an in-home display) was that only the meters of the customers with a demand-response type of electricity rate would have to be equipped with that extra component. However, since there is only one slot in the French smart meter, folding the smart home box in its 'radio module' and using it for 'demand- 
response' functionalities created rivalries as it would endow the actor who would lodge his box in the meter with a de facto market advantage.

This project however was closed down with the argument that a recent European Energy Efficiency directive ${ }^{6}$ required the downstream meter market to remain fully open to competitors. Interestingly, here, it is not the unbundling argument that is at play but another argument about the need for the meter to remain neutral or rather equal for all. It is an argument that is obviously of such a scope that it can't take into account that the French meter has one side dedicated to the grid (the whole meter except the slot and a few connections) and one side dedicated to the consumer (the slot and a few connections), each one having its specifications, projected users, technical norms, and so on. The argument brought here is however of the same order as that of unbundling. This is a view according to which the interface between the market and the non-market that is between the individual and the collective needs to be flat, thus overlooking the material issues of the passage of the collective toward the individual and vice-versa (Grandclément et al. in press).

In both cases, the non-transmission of prices for the sake of the market or the equality of access to the meter are arguments that invoke, at least in the background, the same figure of the consumer. It is that of a market offer chooser, that typically underlies the economic representation of the virtue of free competition: the smart-electricity consumer should be faced with multiple offers in order to get the chance to express its optimizing potential and drive market competition to a socially efficient configuration. In order to realize this view however, the meter now needs to be complemented with an in-competition smart

\footnotetext{
${ }^{6}$ Directive 2012/27/EU on Energy Efficiency - Article 18
} 
home box, supported by private business models, installed downstream from the meter and communicating with it.

\subsubsection{Letting a market for "smart home boxes" develop and leaving the consumer} in the hands of marketing

Following this series of moves that are like the effects of a series of anti-programmes applied to the initial design, the working group finally ended up with the following configuration: a radio module should be installed when needed only. That radio module, when installed, would transmit a price hierarchy (but not a price list) through 'openaccess' waves so that competitors could offer competitive energy management boxes downstream from it and develop business models.

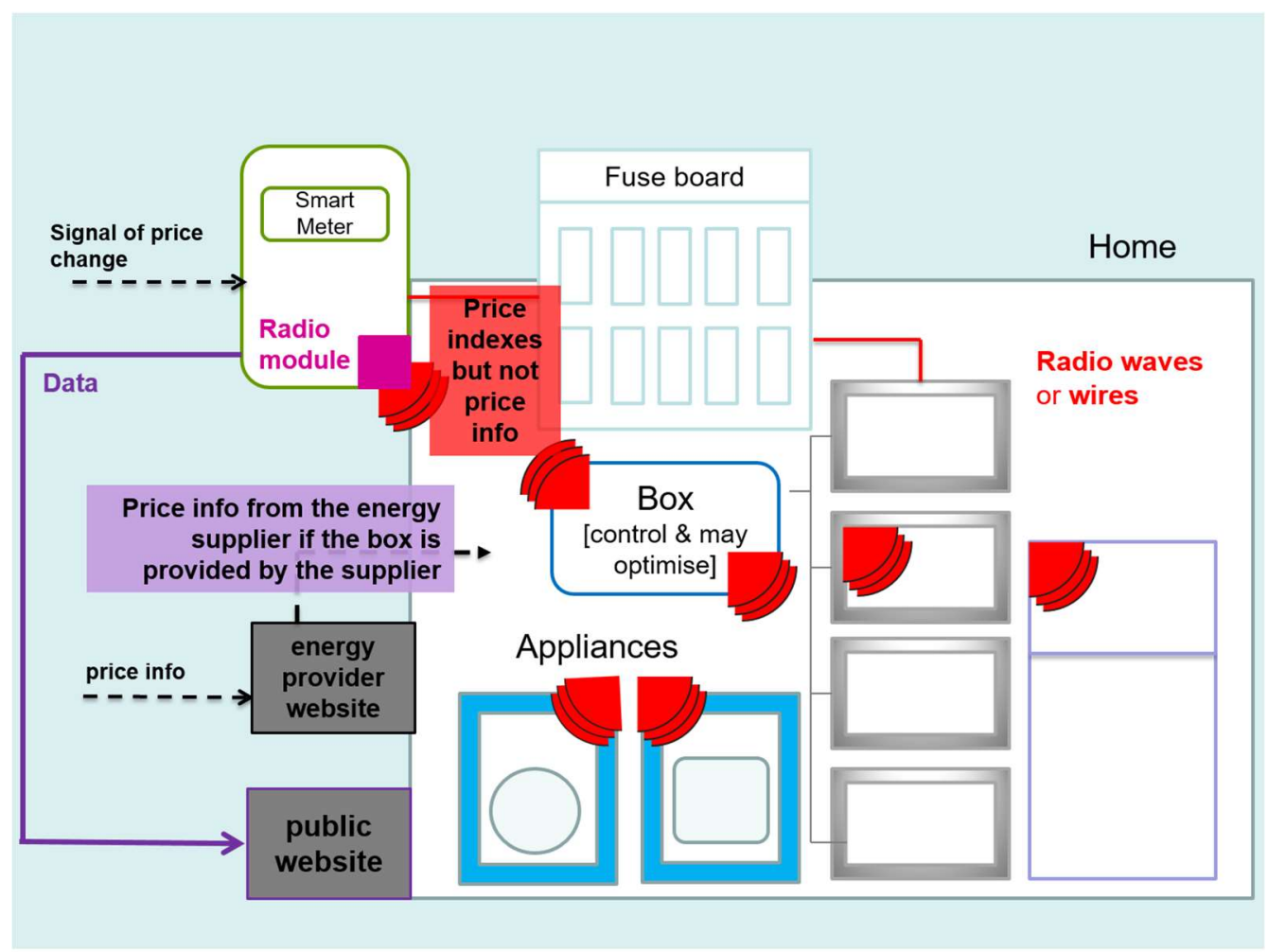

In this final configuration, the consumer could in principle choose separately a box and a rate and then programme his/her box so that it could decode the price hierarchy from the meter. In practice, however, the energy provider (who knows prices) is much more able to do that assemblage of rate and box than the end-user. This assemblage would result in 
bundled offers with elaborate electricity rates, an energy management box and the radio module and perhaps a 'smart' thermostat, an app or a display. In so doing, market actors would render the cost of the smart grid equipment invisible for the final user. Such a 'bundled' offer could comprise for instance a time-varying electricity rate (for instance with peak and off-peak prices) and a compatible pre-programmed box that would allow the consumer to get most 'benefits' from that rate.

In this kind of elaborate bundle of services, the provider keeps the consumer 'under' his hand. The consumer is provisionally captive in the sense of Trompette (2005) and Cochoy (2007). While, according to Cochoy, it is always possible in principle for this kind of provisionally captive customer to change supplier, this is very difficult in practice. Here, what consumer choice is in practice is overlooked by the abstractness of the economic approach to market competition and the 'market chooser' consumer. The figure of the consumer that is at work here is the attached consumer of elaborate market offers, bundled products and services, loyalty programs and other marketing devices.

\section{Discussion}

The process we have just described weaves together several programmes and antiprogrammes for the meter. Their succession results in a sinuous trajectory for the joint design of the functionality of the radio module and of the technical architecture of the smart home. First, there is the project to generate energy savings by systematically conveying quantitative information to the consumer through an in-home display connected to the radio module. This radio module, however, is coveted by commercial actors of the smart home as a micro-sized box that could cheaply control appliances. Second, there is the expectation the smart meter would convey real-time price information allowing any downstream operator to plug its devices and use the information to offer to consumers services such as usage optimization, peak-load shavings, information 
services. However, prices end up circumventing the meter and being provided by the energy provider through a separate internet site. Third, there is the project to have the French smart meter be the obligatory passage point for the technical architecture of the smart home, which because of the unique slot for plugging-in a radio-module raises competition issue, and finally ends up in the de facto requirement that the technical architecture of the smart home includes a downstream box outside of the meter.. Each result of these tensions between programme and anti-programme is accompanied and even performed by a discourse on the proper way to organise the market, that is, to carry out the work of purification between competition and monopoly. Unbundling is the argument most often used but another about keeping competitive ground open is also used to prevent commercial actors from appropriating the empty slot of the meter. Each time, there also is a specific figure of the consumer, in the name of which the technical architecture of the smart home is put forward.

This story shows the ambiguous relation between an abstract economic doctrine instantiating a belief in the emancipatory capacity of market - and allegedly constructing the market as a space for free choice - and the mundane practices of market making and technical design which assemble a capacity to choose. The weirdness and clumsiness of the smart home designs we have described invites us to reflect further on the agencing of choice that each of the situations entails. The designs are weird and clumsy because the availability of information, especially that of price, is limited in the name of the market. They are weird and clumsy also because the whole point of making the smart meter the obligatory passage point of the smart home would have been to avoid the clumsy system of box and cables that is finally deployed in addition to the smart meter. The situation is reminiscent of the point made by Franck Cochoy that empirical markets never fulfil simultaneously all of the rules of the pure and perfect market (Cochoy, 1999). 
There are also three figures of the consumer that are convoked in the course of our case study: the behavioural energy saver, the market offer chooser, and the attached consumer, yet each with quite different status and reach.

The first two (behaviourist and market offer chooser) are consumer-centred and advocate versions of the consumer that are doctrinally compatible with classical/neoliberal economics. Behavioural approaches in micro-economics endow the consumer with a set of values that is larger than that of the rational self-interested market offer chooser, but they are both invoked in our process so as to design a market in which the consumer is supposedly sovereign: his/her values (in the first case) or preferences (in the second case) may drive the market to a type of optimum. Our case study does not give a chance for this figure to materialise. Because of intricacies in the technical design of the French meter that are specific to our case study (the unique slot for a radio module), the behaviourist claim interferes with principles of free competition and convokes another (economic) figure: the market offer chooser. In turn, the invocation of this new figure hampers the provision of in-home display and the communication of energy prices through the meter, and restores a place for in-competition boxes at home. And yet, this restoration of competition empowers the designers of smart homes and allows them to rebundle choice: prices do not circulate with electrons but with a bipartite contract whose signatories do not benefit of an equivalent agency and ofthe autonomy they are endowed with in the marketplace. In addition, and this is why we speak of the re-bundling of choice, the contract comes with a set of devices on which the end-user has a limited capacity of action and that contributes to embed energy choices in the overall design of their home. We'd also like to point out that had alternative designs been validated and put in place, they certainly wouldn't have given way to the detached, autonomous, self-contained ideal consumer of the unbundling doctrine. In our story, visions of the behavioural energy saver 
consumer as well as in the market offer chooser are mobilized in scenes in which numerous actants and devices feature. Intermediaries of all sorts are present in all the four architectures of the smart meter and the smart home. The attached consumer is not the exception, it is the rule.

\section{Conclusion}

To conclude, the case study points out a singular articulation between the deployment a mundane artefact - an electric meter - and the profound changes that deploying such an ordinary thing entails, notably because it is a story in which politics passes through the market. What we observe is that in attempting to fill the market with competition, the unbundling doctrine also fills the market with politics which unfold unnoticed.

The first conclusion of this story has to do with the emergence of a figure of the consumer in smart grids. The case points out a struggle to inscribe the consumer in the meter. Three different figures are at play in this struggle: a behavioural energy saver; a market offer chooser and an attached consumer. The struggle between these figures and the outcome of the process suggests that even figures that are doctrinally compatible with classical/neoliberal economics and advocate the consumer as a self-contained totality, do not make these figures come true. Rather, they lay the ground for an attached consumer to emerge, suggesting that attachments and (usually provisional) capture is not just $a$ possibility but a fate.

The second conclusion is that a rather abstract economic doctrine (unbundling) is countered in this struggle by concrete techno-material marketing efforts which result in twists and obvious contradictions in that doctrine. The final consumer is deprived of price information, information that the economic doctrine sees as a basic condition for the functioning of a market. We end up with the paradoxical result that in the name of the market, prices shall not be disclosed to the final consumer. Such a paradox is part of an 
ambiguous relation between this doctrine and the mundane market making practices that seem to circumvent it. While the profound politics of (attached) consumer choice could be said to lie in the tiny details of these marketing practices, such practices could not unfold unnoticed had the terrain of market not be set as demarcated from politics by the (unbundling) economic doctrine itself. Thus, while our analysis joins with recent works emphasizing that politics is in the inside of markets, we add to these works in two ways. First, by instantiating the role of mundane techno-material practices of market making. Second, by emphasizing the profound role of economics in setting market as a place for the politics of agencing choice to happen unnoticed.

\section{Acknowledgements}

This work was carried out with the financial support of the French National Research Agency (ANR, Programme sociétés innovantes, convention 2011- SOIN-003-01, projet COLLENER).

The content of this paper does not reflect the official opinion of the ANR, the CNRS, the CIRED or any of the organisations and institutions cited in the paper. Responsibility for the information and views expressed in the article lies entirely with the authors.

We gratefully thank Stefan Schwarzkopf and Tomas Ariztia and two anonymous reviewers for invaluable feedback on previous versions of this paper when it was presented at the EGOS conference in 2015 and at the NUMIES seminar in 2016 and first submitted to this journal. We warmly extend our thanks to Dan Neyland, Vera Ehrenstein and Sveta Milyaeva for their support and feedback in the process of finalizing this article. All errors remain, of course, ours. 


\section{References}

Abi Ghanem, Dana, and Sarah Mander. 2014. 'Designing Consumer Engagement with the Smart Grids of the Future: Bringing Active Demand Technology to Everyday Life'. Technology Analysis \& Strategic Management 26 (10): 1163-75.

Akrich, Madeleine, 1992. 'The de-scription of technical objects', in: Bijker, W.E., Law, J. (Eds.), Shaping Technology / Building Society, MIT Press, Cambridge: Mass, pp. 205-224.

Akrich, Madeleine, and Bruno Latour. 1992. 'A summary of a convenient vocabulary for the semiotics of human and nonhuman assemblies', in: Bijker, W.E., Law, J. (Eds.), Shaping Technology / Building Society. MIT Press, Cambridge, Mass, pp. 259-263.

Ansaloni, Matthieu, Pascale Trompette, and Pierre-Paul Zalio. 2017. 'Le marché comme forme de régulation politique. Revue française de sociologie 58 (3): 359-74.

Aráujo, Luís, John Finch, and Hans Kjellberg, eds. 2010. Reconnecting Marketing to Markets. Oxford: Oxford University Press.

Ariztia, Tomas. 2015. 'Unpacking insight: How consumers are qualified by advertising agencies'. Journal of Consumer Culture 15 (2): 143-62.

Arnould, Eric J., and Craig J. Thompson. 2005. 'Consumer Culture Theory (CCT): Twenty Years of Research'. Journal of Consumer Research: 31 (4): 868-882.

Breslau, Daniel. 2003. 'Economics invents the economy: Mathematics, statistics, and models in the work of Irving Fisher and Wesley Mitchell'. Theory and Society 32, $379-411$.

Breslau, Daniel. 2013. 'Designing a Market-like Entity: Economics in the Politics of Market Formation'. Social Studies of Science 43 (6): 829- 851.

Breslau, Daniel. 2018. 'Assembling economic actors: time-varying rates and the new electricity consumer'. In Philosophy and Interdisciplinary Social Science: A Dialogue. Bloomsbury Press.

Bulkeley, Harriet, Gareth Powells, and Sandra Bell. 2014. 'Smart Grids and the Governing of Energy Use: Reconfiguring Practices?' In Social Practices, Interventions and Sustainability: Beyond Behaviour Change., edited by Y. Strengers and C. Maller, 112-26. London, New York: Routledge.

Callon, Michel, ed. 1998. The Laws of the Markets. Sociological Review Monographs. Oxford: Blackwell Publishers/The Sociological Review. 
Callon, Michel. 2007. 'What Does It Mean to Say That Economics Is Performative?' In Do Economists Make Markets? : On the Performativity of Economics, Donald MacKenzie, Fabian Muniesa, and Lucia Siu, eds, 311-57. Princeton, NJ: Princeton University Press.

Callon, Michel. 2016. 'Revisiting Marketization: From Interface-Markets to MarketAgencements'. Consumption Markets \& Culture 19 (1): 17-37.

Callon, Michel, Cécile Méadel, and Vololona Rabeharisoa. 2002. 'The Economy of Qualities'. Economy and Society 31 (2): 194-217.

Callon, Michel, and Fabian Muniesa. 2005. 'Economic Markets as Calculative Collective Devices'. Organization Studies 26 (8): 1229-50.

Callon, Michel, Yuval Millo, and Fabian Muniesa, eds. 2007. Market Devices. The Sociological Review. Oxford: Blackwell Publishing.

Callon, Michel, Madeleine Akrich, Sophie Dubuisson-Quellier, Catherine Grandclément, Bruno Latour, Alexandre Mallard, Cécile Méadel, Fabian Muniesa, and Vololona Rabeharisoa. 2013. Sociologie des agencements marchands: textes choisis. Paris: Presses des Mines.

Chessel, Marie-Emmanuelle. 2012. Consommateurs engagés à la Belle Époque. La ligue sociale d'acheteurs. Paris: Presses de Sciences Po.

Cochoy, Franck. 1999. Une histoire du marketing: discipliner l'économie de marché. Paris: La Découverte.

Cochoy, Franck. 2002. Une sociologie du packaging ou l'âne de Buridan face au marché. Paris: Presses Universitaires de France.

Cochoy, Franck, and Catherine Grandclément. 2005. 'Publicizing Goldilocks' Choice at the Supermarket: The Political Work of Shopping Packs, Carts and Talk'. In Making Things Public: Atmospheres of Democracy, edited by Bruno Latour and Peter Weibel, 646-59. Karlsruhe and Cambridge: MA / London: ZKM/The MIT Press.

Cochoy, Franck, Joe Deville, and Liz McFall, ed. 2017. Markets and the arts of attachments. Routledge.

Cour des Comptes [French Auditors Court]. 2018. 'Rapport public annuel 2018', Chapitre 4.

Darby, Sarah. 2006. 'The Effectiveness of Feedback on Energy Consumption: A Review for DEFRA of the Literature on Metering, Billing and Direct Displays'. DEFRA. 
Davies, William. 2014. The Limits of Neoliberalism: Authority, Sovereignty and the Logic of Competition. Sage.

du Gay, Paul. 1996. Consumption and Identity at Work. Sage.

Dubuisson-Quellier, Sophie. 2009. La consommation engagée. Paris: Presses de Sciences Po.

Dubuisson-Quellier, Sophie, ed. 2016. Gouverner les conduites. Paris: Presses de Sciences Po.

Dujarier, Marie-Anne. 2008. Le travail du consommateur : De McDo à eBay : comment nous coproduisons ce que nous achetons. Paris : La Découverte.

Ehrhardt-Martinez, Karen, Kat A. Donnelly, and John A. Skip Laitner. 2010. 'Advanced Metering Initiatives and Residential Feedback Programs: A Meta-Review for Household Electricity-Saving Opportunities'. Report E105. ACEEE.

EPRI. 2009. 'Residential Electricity Use Feedback: A Research Synthesis and Economic Framework'. Electric Power Research Institute (EPRI), Palo Alto, CA, Report 1016844.

Foucault, Michel. 2004. Naissance de la biopolitique: Cours au Collège de France. Paris: Seuil.

Fridman, Daniel. 2010. 'A new mentality for a new economy: performing the homo economicus in Argentina (1976-83)'. Economy and Society 39 (2): 271-302.

Geiger, Susi, Debbie Harrison, Hans Kjellberg, and Alexandre Mallard. 2015. Concerned Markets: Economic Ordering for Multiple Values. Cheltenham, UK: Edward Elgar Pub.

Graham, Stephen, and Simon Marvin. 2001. Splintering Urbanism: Networked Infrastructures, Technological Mobilities and the Urban Condition. London: Routledge.

Grandclément, Catherine, Magali Pierre, Elizabeth Shove, and Alain Nadaï. In Press. 'Contentious Interfaces: Exploring the Junction between Collective Provision and Individual Private Consumption'. In Infrastructures in Practice: The Evolution of Demand in Networked Societies, edited by Elizabeth Shove and Frank Trentmann. Routledge.

Hansen, Meiken, and Mads Borup. 2018. 'Smart Grids and Households: How Are Household Consumers Represented in Experimental Projects?' Technology Analysis \& Strategic Management 30 (3): 255-67. 
Jabko, Nicolas. 2006. Playing the Market: A Political Strategy for Uniting Europe, 19852005. Ithaca, NY: Cornell University Press.

Kjellberg, Hans, and Claes-Fredrik Helgesson. 2010. 'Political Marketing . Multiple Values, Performativities and Modes of Engaging'. Journal of Cultural Economy 3 (2): 279-97.

Latour, Bruno. 1996. Aramis or the Love of Technology. Harvard University Press.

Lewis, Philip E., Christophe Dromacque, Sean Brennan, Jessica Stromback, and Daria Kennedy. 2012. 'Empower Demand 2. Energy Efficiency through Information and Communication Technology - Best Practice Examples and Guidance'. VaasaEET for the European Smart Metering Industry Group. http://esmig.eu/sites/default/files/final_empower_2_demand_report_final_distr2. pdf.

Lury, Celia. 1996. Consumer Culture. New Brunswick: Rutgers University Press.

MacKenzie, Donald A. 1990. Inventing Accuracy: An Historical Sociology of Nuclear Missile Guidance. Inside Technology. Cambridge, Mass: MIT Press.

MacKenzie, Donald, Fabian Muniesa, and Lucia Siu, ed. 2007. Do economists make markets?: on the performativity of economics. Princeton, NJ: Princeton University Press.

Marres, Noortje. 2009. 'Testing Powers of Engagement: Green Living Experiments, the Ontological Turn and the Undoability of Involvement'. European Journal of Social Theory 12 (1): 117-33.

McFall, Liz. 2014a. 'What Have Market Devices Got to Do with Public Policy?' In L'instrumentation de l'action Publique: Controverses, Résistances, Effets, edited by Charlotte Halpern, Pierre Lascoumes, and Patrick Le Galès, Paris: Presses de Sciences Po, 119-42.

2014b. Devising Consumption: Cultural Economies of Insurance, Credit and Spending. Abingdon: Routledge.

McFall, Liz, Joe Deville, and Franck Cochoy. 2017. 'Introduction: Markets and the Arts of Attachment'. In Market Attachments, edited by Liz McFall, Joe Deville, and Franck Cochoy, Abingdon: Routledge.

Mitchell, Tim. 1998. 'Fixing the Economy'. Cultural Studies 12 (1): 82-101.

Mitchell, Tim. 2008. 'Rethinking Economy’. Geoforum 39 (3): 1116-1121. 
Mosca, Manuela. 2008. 'On the Origins of the Concept of Natural Monopoly: Economies of Scale and Competition'. The European Journal of the History of Economic Thought 15 (2): 317-53.

Muniesa, Fabian. forthcoming. 'How to Spot the Behavioural Shibboleth and What to Do About It", in: Marres, N., Guggenheim, M., Wilkie, A. (Eds.), Inventing the Social. London: Mattering Press.

Muniesa, Fabian, Yuval Millo, and Michel Callon. 2007. 'An Introduction to Market Devices'. In Market Devices, edited by Michel Callon, Yuval Millo, and Fabian Muniesa, 1-12. Oxford: Blackwell Publishing.

Muniesa, Fabian. 2014. The Provoked Economy: Economic Reality and the Performative Turn. Routledge.

Naus, Joeri, and Hilje M. van der Horst. 2016. 'Accomplishing Information and Change in a Smart Grid Pilot: Linking Domestic Practices with Policy Interventions'. Environment and Planning C: Government and Policy, August.

Neyland, Daniel, Véra Ehrenstein, and Sveta Milyaeva. xxxx. 'Mundane Market Matters: From ordinary to profound and back again'. Journal of Cultural Economy.

Rosanvallon, Pierre. 1999. Le capitalisme utopique. Histoire de l'idée de marché. Paris: Seuil.

Schwarzkopf, Stefan. 2011. 'The Political Theology of Consumer Sovereignty: Towards an Ontology of Consumer Society’. Theory, Culture \& Society 28 (3): 106-29.

Shove, Elizabeth. 2003. Comfort, Cleanliness and Convenience: the Social Organization of Normality. Oxford: Berg.

Shove, Elizabeth. 2010. 'Beyond the ABC: Climate Change Policy and Theories of Social Change'. Environment and Planning A 42 (6): 1273 - 1285.

Skjølsvold, Tomas Moe, Marianne Ryghaug, and Thomas Berker. 2015. 'A Traveler's Guide to Smart Grids and the Social Sciences'. Energy Research \& Social Science, 9 (September): 1-8.

Skjølsvold, Tomas Moe, Susanne Jørgensen, and Marianne Ryghaug. 2017. 'Users, Design and the Role of Feedback Technologies in the Norwegian Energy Transition: An Empirical Study and Some Radical Challenges'. Energy Research \& Social Science 25 (March): 1-8.

Storper, Michael. 2000. "Lived effects of the contemporary economy: Globalization, inequality, and consumer society". Public Culture 12 (2): 375-410. 
Stromback, Jessica, Christophe Dromacque, and Mazin H. Yassin. 2011. 'Empower Demand: The Potential of Smart Meter Enabled Programs to Increase Energy and Systems Efficiency: A Mass Pilot Comparison'. VaasaETT, Global Energy Think Tank, Project funded by the European Smart Metering Industry Group. http://esmig.eu/sites/default/files/empower-demand-report.pdf.

Thaler, Richard H, and Cass R. Sunstein. 2008. Nudge: Improving Decisions About Health, Wealth, and Happiness. Yale University Press.

Throndsen, William, and Marianne Ryghaug. 2015. 'Material Participation and the Smart Grid: Exploring Different Modes of Articulation'. Energy Research \& Social Science, 9 (September): 157-65.

Trentmann, Frank. 2006. "Knowing Consumers - Histories, Identities, Practices. An Introduction". In The making of the consumer: knowledge, power and identity in the modern world, 1-27. Oxford: Berg Publishers.

Wyatt, Sally. 2003. 'Non-Users Also Matter: The Construction of Users and Technologies'. In How Users Matter: The Co-Construction of Users and Technologies, edited by Nelly Oudshoorn and Trevor Pinch, 41-56. 